\title{
High Current, Low Energy Electron Beams Produced During the High Current Phase of a Pseudospark*
}

\author{
T-Y Hsu, R. Liou, G. Kirkman**, and M. A. Gundersen \\ Department of Electrical Engineering-Electricophysics \\ University of Southern California \\ Los Angeles, CA 90089-0484 USA
}

\begin{abstract}
Electron beams produced by the superemissive cathode of a back-lighted thyratron (BLT) or pseudospark are reported. The cathode is highly emissive, or superemissive during conduction, producing a current density of $>10^{4} \mathrm{~A} / \mathrm{cm}^{2}$ over an area of $\sim 1 \mathrm{~cm}^{2}$. During conduction, electrons produced by the cathode are accelerated through the anode central hole, forming a beam that can be extracted. An electron beam of 120 A has been observed with an efficiency of $10 \%$. The beam current increase with increasing applied voltages and decreasing gas pressure. A pulse forming network can transfer energy to an electron beam with a duration of the discharge pulse. The superemissive beam has energy of $\sim 400 \mathrm{eV}$ corresponding to the cathode sheath voltage. Beam extraction into a low pressure area ( $<7 \mathrm{mT}$ Torr) was achieved by a differential pumping scheme with a guiding magnetic field. A flat-top spatial profile of the beam current distribution is obtained after the beam propagation through a narrow dielectric tube.
\end{abstract}

\section{INTRODUCTION}

The back-lighted thyratron (BLT) or pseudospark structure have been studied for producing pulsed electron beams and proposed as a potentially high-quality beam source for high power applications. Pseudospark-produced electron beams during and briefly before voltage breakdown have been reported, and is related to the hollow cathode (HC) discharge. [1-4] Electron beams generated by the back-lighted thyratron (BLT) during the conduction phase, which is related to the superemissive cathode (SEC) discharge, also have been reported.[5-7] The SEC in the BLT is self-heated, very robust, and produces extremely high, uniform current.[8-10] In the low pressure glow discharge mode, typical of the BLT and the pseudospark, high current density on the order of $10 \mathrm{kA} / \mathrm{cm}^{2}$ over an area of $1 \mathrm{~cm}^{2}$ have been observed. New evidence and theory show that vacuum arc type discharges also present on the cathode surface near the center hole during the SEC conduction phase. [11] During the conduction of the BLT, the voltage across the gap is dropping down to the order of a hundred volts. Most of the voltage drop is across the cathode fall region which forms a thin layer of few micron on the cathode surface. The electrons generated by the superemissive cathode are accelerated across the cathode fall region and inject into the bulk plasma. The formation and extraction of the SEC electron beam was simulated and predicted by Bauer and Gundersen.[12,13] In this report, we present further data

* This work was supported in part by the U.S. Army Research Office, SDIO through the U.S. Office of Naval Research, and the Lawrence Livermore National Laboratory.

** G. Kirkman is with Integrated Applied Physics, Inc., Waltham, MA. related to characteristics of the SFC heam, the influence of operation parameters, extraction of the SEC beam into low pressure area, and the effect of dielectric tube.

\section{EXPERIMENTS AND RESULTS}

The experimental setup for the SEC beam diagnotic is the same as in reference.[5] Figure 1 shows typical discharge currents and beam currents produced by the BLT with an external capacitor for energy transfer. The beam current extended well into the falling portion of the discharge current indicating a SEC beam, as distinct from a HC beam. These electrons are injected from the cathode fall region of the BLT during the high-current conduction phase. The beam current terminates shortly after the maximum of the discharge current, which is a result of fast voltage decay across the BLT during conduction. Experiments also show that the bean current increases with applied voltage (Figure 1) and with decreasing gas pressure within the operation range of 60 to $20 \mathrm{~m}$ Torr argon gas. This suggests that the voltage holdoff capability of the BLT, thus the SEC-produced beam current, can be scaled by a multiple-gap structure.[14]

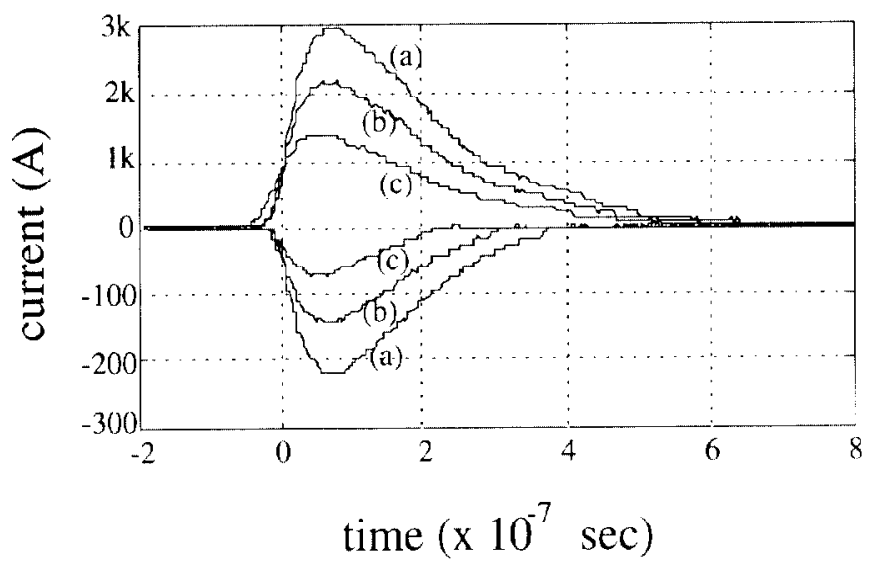

FIG. 1 The discharge currents (positive) and the beam currents (negative) at $50 \mathrm{~m}$ Torr argon, applied voltages of (a) $10 \mathrm{kV}$, (b) $15 \mathrm{kV}$, and (c) $20 \mathrm{kV}$, using a $40 \mathrm{nF}$ charging capacitor and a $5 \mathrm{ohm}$ load resistor.

The heam characteristics has been studied with several different pulse forming network (PFN) as energy transfer unit. Figure 2 shows typical beam pulses and the discharge current at different gas pressures. The beam has about the same duration as the discharge current. The magnitude of beam pulse also increases with increasing applied vollage and with decreasing gas pressure as shown in Figure 2. A voltage measurement shows a significant amount of voltage $(\sim$ few hundred volts) is maintained and not decaying across the BLT 
during current discharge. Measurements indicate that the voltage across BLT increases with increasing applied voltage.

Another setup with crossed glass drift tube, which provide a portion of drift region with wider cross section, is constructed to look at the Larmor radii of beam electrons at different applied voltage. The magnet is placed right below the crossed region of the glass drift tube. Results show that the Larmor radius of the SEC beam increases with increasing applied votage, indicating the energy of the SEC beam, just like the energy of the $\mathrm{HC}$ beam, increases with applied voltage. The data shows the Larmor radius of the SEC electrons is $0.85 \mathrm{~cm}$ at applied voltage of $20 \mathrm{kV}$. Knowing the magnetic field at tube center ( $\sim 80$ Gauss), the estimated energy of the SEC beam is $420 \mathrm{eV}$. At applied voltage of 13 $\mathrm{kV}$ the SEC beam energy is $170 \mathrm{eV}$.

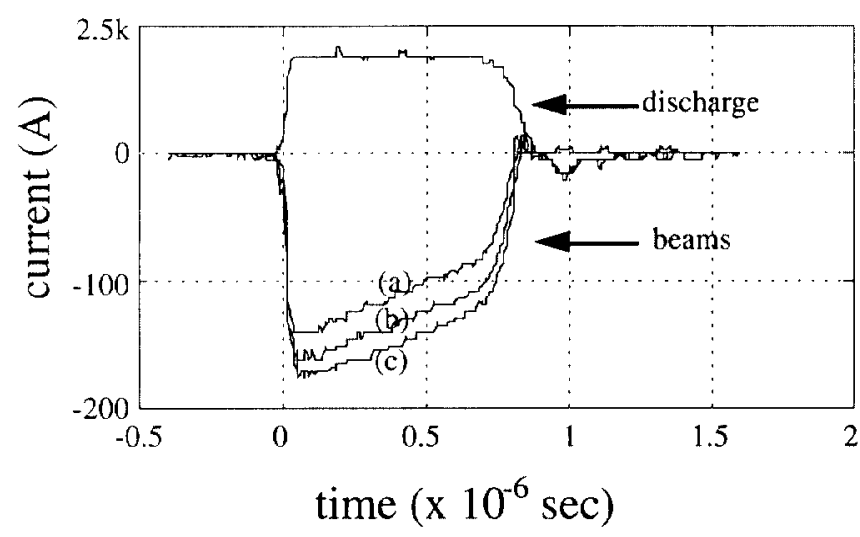

FIG. 2 The discharge and the bcam currents at $15 \mathrm{kV}$ applicd voltage and argon pressures of (a) 50, (b) 40, and (c) 30 mTorr, using a PFN of 750 ns pulse for energy transfer.

The behavior of the SEC electron beam in the low pressure ( $<10 \mathrm{mTorr}$ ) area is studied by a differential pumping scheme. The gas is fed in from the BLT cathode side and pumped out from the diagnostic region. The differential pumping effect results from the central holes of electrodes and anode back wall. A longitudinal magnetic field is generated for focusing the electron beam. Figure 3 shows the increase of

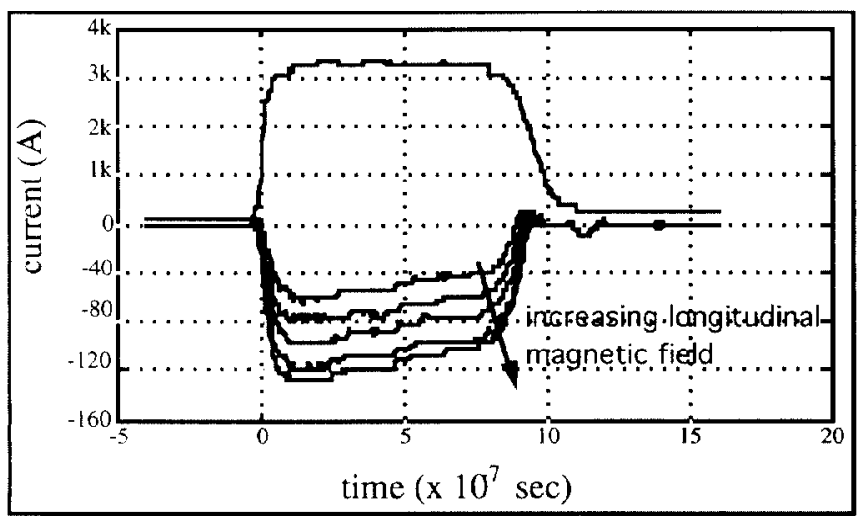

FIG. 3 The discharge current (positive) and beam currents (negative) at $15 \mathrm{kV}$ applied voltage and $6 \mathrm{mTorr}$ argon pressure in the diagnostic region when the magnetic field increases from 0 to 400 Gauss.

beam current with increase of magnetic field at argon pressure of $7 \mathrm{mTorr}$ in the diagnostic region. An electron beam of
$>120 \mathrm{~A}$ is extracted into low pressure area by this simple setup.An electron beam transporting through a dielectric tube results in beam collimation and focusing. This is mainly due to the impinging of the electron beam front on the tube walls, resulting in surface breakdown and positive ion ejection, compensating the space charge of beam electrons.[15-17] In this case, the tube diameter should not significantly exceed that of the beam exiting the anode, since the charge compensation effect is drastically reduced. The SEC beam has been guided through a glass tube of $12 \mathrm{~cm}$ in length and $1 \mathrm{~cm}$ in diameter right behind the anode back wall. The spatial profile of the BLT electron beam was measured $18 \mathrm{~cm}$ away from the anode back wall with and without the glass tube (Figure 4). Based on the data, it is evident that the beam is effectively collimated when using the small diameter dielectric tube. At $18 \mathrm{~cm}$ downstream, the central area of $\sim 1 \mathrm{~cm}^{2}$ of the collimated electron beam is very uniform, with a current density exceeding $60 \mathrm{~A} / \mathrm{cm}^{2}$.

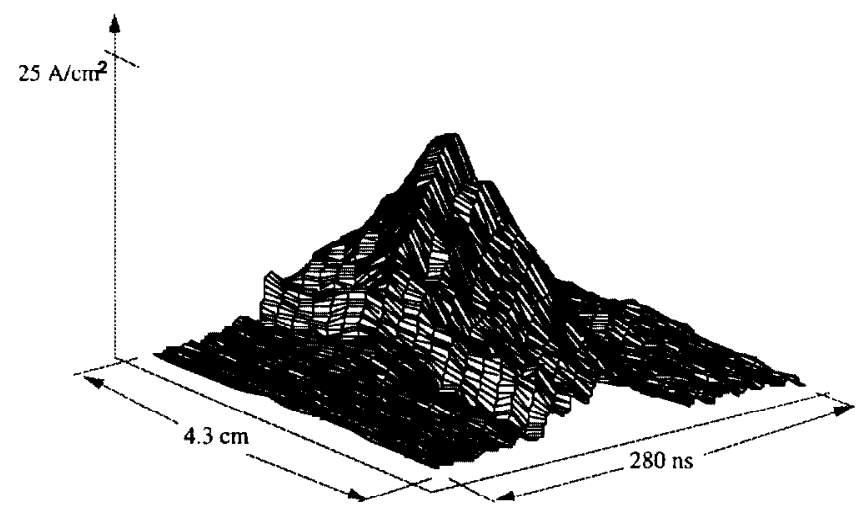

(a)

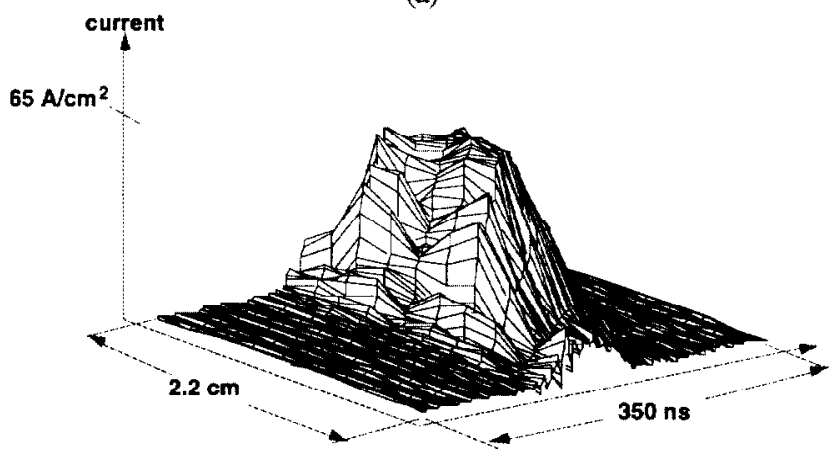

(b)

FIG. 4 The spatial and temporal profile of the BLT produced electorn beam (a) without and (b) with the glass tube.

\section{CONCLUSION}

An SEC electron beam produced by the BLT with a capacitive energy storage is terminated shortly after the maximum of discharge current and is a result of fast decay of voltage across the BLT. With a PFN as the energy storage, the BLT maintains a significant amount of voltage during the whole discharge pulse and generates a beam pulse of equal duration. The energy, current, and duration of the SEC 
electron beam can be modified through the control of external circuit elements and operation parameters. The spatial uniformity of the SEC beam is improved by the guiding of a dielectric tube. The fact that the SEC electron beam has extremely high current density and can be modified by adjusting several different operation parameters makes the BLT an attractive candidate as a high power electron beam source for many applications, including accelerators and laser ionization.

\section{REFERENCES}

[1] W. Benker, J. Christiansen, K. Frank, H. Gundel, W. Hartmann, T. Redel, and M. Stetter, "Generation of intense pulsed electron beams by the pseudospark discharge," IEEE Tran. Plasma Sci., 17 (5), 754 (1989).

[2] E. Boggasch, T. A. Fine and M. J. Rhee, "Measurement of Pseudospark Produced Electron Beam," Bull. Amer. Phys. Soc., 33, 1951 (1988).

[3] P. Choi, H. H. Chuaqui, M. Favre, E. S. Wyndham, "An Observation of Energetic Electron Beams in Low Pressure Linear Discharges," IEEE Trans. Plas. Sci. PS15,428 (1987).

[4] H. Pak and M. Kushner, "Multi-beam-bulk model for electron transport during communication in an optically triggered pseudospark thyratron," Appl. Phys. Lett., 57, $1619(1990)$.

[5] T-Y Hsu, R-L Liou, G. Kirkman-Amemiya, and M. A. Gundersen," Electron beam generation from a superemissive cathode," Proceedings of the 1991 Particle Accelerator Conference, 1990 (1991).

[6] T-Y Hsu, R-L Liou, G. Kirkman-Amemiya, and M. A. Gundersen, "Electron beams produced by the superemissive cathode," Proceedings of the Eighth IEEE International Pulsed Power Conference, 567 (1991).

[7] T-Y Hsu, and M. A. Gundersen, "A high-power electron beam source based on the superemissive cathode," Appl. Phys. Lett., 61 (21), 2515 (1992).
[8] W. Hartmann and M. Gundersen, "Origin of anomalous emission in superdense glow discharge," Phys. Rev. Lett., 60, 2371 (1988).

[9] W. Hartmann, V. Dominic, G.F. Kirkman, and M.A. Gundersen, "Evidence for large area super-emission into a high current glow discharge," App. Phys. Lett. 53 (18), 1699 (1988).

[10] W. Hartmann, V. Dominic, G. Kirkman, and M.A. Gundersen, "An analysis of the anomalous high current cathode emission in pseudo-spark and BLT swilches," J. Appl. Phys., 65 (11), 4388 (1989).

[11] A. Anders, S. Anders, and M. A. Gundersen, "Model for explosive electron emission in a pseudospark superdense glow." submitted to Phys. Rev. Lett.

[12] H. Bauer and M. A. Gundersen, "Penetration and equilibration of injected electrons into a high-current hydrogen pseudospark-type plasma," J. Appl. Phys., 68 (2), 512 (1990).

[13] H. Bauer and M. A. Gundersen, "High current plasma based electron source," Appl. Phys. Lett., 57 (5),434 (1990).

[14] T-Y Hsu, G. Kirkman-Amemiya, and M. A. Gundersen, "Multiple-gap back-lighted thyratrons for high power applications," IEEE Trans. Elec. Devices, 38 (4), 717 (1991).

[15] R. G. Little, R. Lowell, and J. R. Uglum, "Cavity current enhancement by dielectrics", IEEE Trans. Nuc. Sci. NS-21, 249 (1974).

[16] R. G. Little, J. R. Uglum, and R. A. Lowell, "Cavity IEMP enhancement by diclectric walls", IEEE Trans. Nuc. Sci. NS-22, 2351 (1975).

[17] B. A. Koval, and G. F. Ozur, "Transport of a nonrelativistic high-current electron beam in a vacuum dielectric channel in a external magnetic field", Sov. Phys. Tech. Phys. 31, 726 (1986). 